\title{
NORTHERN BOBWHITE HABITAT SELECTION IN RELATION TO BRUSH MANAGEMENT IN THE ROLLING PLAINS OF TEXAS
}

\author{
Dean Ransom, Jr.1,4, Roel R. Lopez², Gerral G. Schulz ${ }^{1}$, and Joel S. Wagner ${ }^{3}$
}

\begin{abstract}
Many rangelands in the southwestern United States provide quality habitat for Northern Bobwhites (Colinus virginianus). These same habitats are frequently managed for livestock production and thus are subjected to various brush management practices that are meant to enhance forage production. Bobwhites rely on woody cover for food, thermal and loafing cover, and protection from avian predators. Implementing brush management practices that reflect bobwhite requirements is important for managing usable space and viable populations. We described the structural vegetative characteristics associated with bobwhite locations and random locations on native rangelands in the upper Rolling Plains of Texas that are dominated by honey mesquite (Prosopis glandulosa) and managed with aerial herbicide and prescribed fire. We also used binary logistic regression to model habitat selection; the initial model was built using $67 \%$ of the data $(n=179$ used-random paired points) and then validated using the remaining $33 \%$ of the data $(n=$ 88 used-random paired points). Locations used by bobwhites had significantly larger mean values of percent brush canopy cover, visual obstruction, and angle of obstruction than did random locations; random locations had a greater mean value of percent bare ground than locations used by bobwhites. The resulting logistic regression model contained only the angle of obstruction; the model had an $80 \%$ probability of correctly classifying used and random locations based on the area under the receiver operating curve (ROC). The model maintained a high classification probability when applied to the smaller validation data set, with an area under the ROC of 0.78 .
\end{abstract}

Key words: brush management, Colinus virginianus, habitat selection, Northern Bobwhite, prescribed fire, Texas.

The recent history of North American rangelands has been characterized as one of increasing encroachment, establishment, and density of woody vegetation (brush) resulting from natural fire suppression coincident with the movement and improper management of livestock (Archer et al. 1988, Archer 1989). Beginning in the 1940s and 1950s, early efforts at brush management focused on mechanical and chemical techniques (Fulbright and Guthery 1995, Koerth 1995), and since that time, a mature body of management theory and practical applications has evolved to manage the encroachment of woody plants on rangeland ecosystems (Scifres 1980, Scifres and Hamilton 1993, Fulbright and Guthery 1995, Koerth 1995, Riggs et al.1995).

Many rangeland systems in the United States provide quality habitat for Northern Bobwhites (Colinus virginianus). Bobwhites rely on woody cover for food (Jackson 1969), thermal and loafing cover (Renwald et al. 1978, Johnson and Guthery 1988, Forrester et al. 1998), and protection from avian predators
(Jackson 1969, Guthery 1986, Kopp et al. 1998). Implementing brush management practices that reflect bobwhite requirements is important to managing usable space and maintaining viable populations (Guthery 1997, Spears et al. 1993). Although plant manipulation techniques may reduce the total abundance and diversity of woody plants in some situations, more often it is the structural attributes of shrub cover (e.g., height, canopy cover, and visual obstruction) that are important to bobwhite populations (Johnson and Guthery 1988, Fulbright and Guthery 1995, Kopp et al. 1998, Cram et al. 2002, Hiller and Guthery 2005).

Brush management techniques have historically been applied without regard for wildlife populations and their habitat requirements (Scifres 1980). Renwald et al. (1978), for example, documented detrimental effects from prescribed fire on lotebush (Ziziphus obtusifolia), a woody shrub important to bobwhites for loafing and escape cover; recovery time for this shrub to become suitable for bobwhites was about 6 years. With the increasing popularity

\footnotetext{
${ }^{1}$ Box 1658, Texas Agricultural Experiment Station, Vernon, TX 76384.

${ }^{2}$ Department of Wildlife and Fisheries Sciences, Texas A\&M University, College Station, TX 77843

${ }^{3}$ Texas Parks and Wildlife Department, Hallettsville, TX 77964.

${ }^{4}$ E-mail: rdransom@ag.tamu.edu
} 


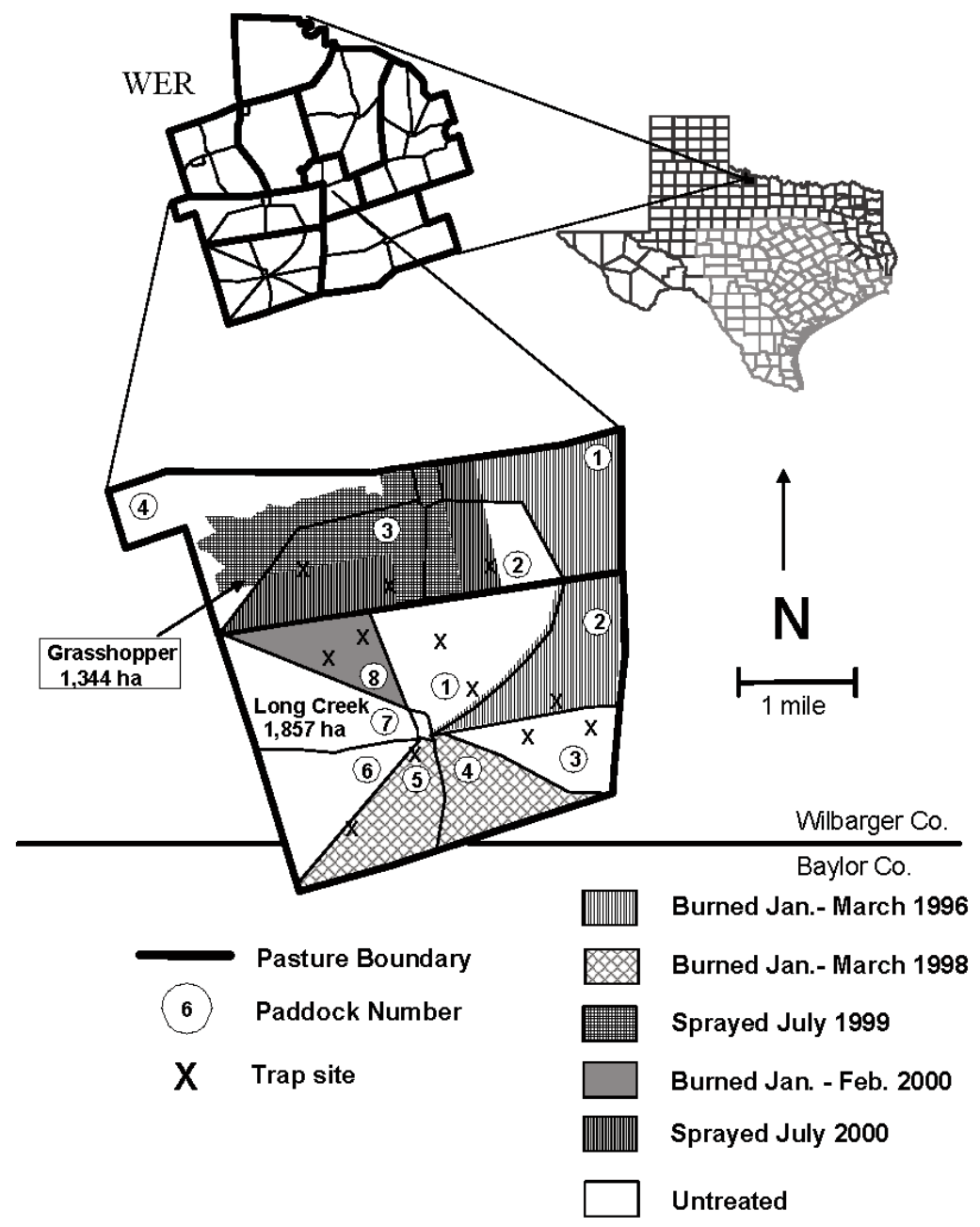

Fig. 1. Location of the Northern Bobwhite study sites and allocation of prescribed fire and herbicide treatments on the Waggoner Experimental Ranch in the Rolling Plains of northern Texas.

of lease hunting and the economic importance of lease hunting to private landowners, wildlife management on rangelands has become a primary land-management objective. As a result, there is greater impetus for brush management to address the habitat requirements of targeted wildlife species (Adams et al. 1992).

To further our understanding of bobwhite ecology and the role of brush cover in habitat selection by bobwhites in the northeastern portion of the Rolling Plains of Texas, we quantified the structural characteristics of bobwhite locations and random locations and then modeled habitat selection on the basis of habitat attributes in a rangeland system dominated by honey mesquite (Prosopis glandulosa) and managed with aerial herbicide and prescribed fire.

\section{Study AREA}

Our study took place on the 12,000-ha Waggoner Experimental Ranch (WER; latitude $33^{\circ} 50^{\prime} \mathrm{N}$, longitude $99^{\circ} 5^{\prime} \mathrm{W}$ ) in Wilbarger County near Vernon, Texas (Fig.1). The WER was part of the $>200,000$ ha of W.T. Waggoner Ranch located in the Rolling Plains ecological region of Texas (Gould 1975). The climate is continental, with an average growing season of 220 days and a mean annual precipitation of $648 \mathrm{~mm}$. Precipitation peaked seasonally in May and September. Mean monthly minimum 
and maximum temperatures ranged from a minimum of $-2.3^{\circ} \mathrm{C}$ in January to a maximum of $36.4^{\circ} \mathrm{C}$ in July. Topography is moderately rolling with elevations ranging from $335 \mathrm{~m}$ to $396 \mathrm{~m}$. Bobwhites have not been hunted on the WER since 1995.

The Rolling Plains ecological region is part of the southern extension of the Great Plains, and historically, this region was a grassland or grassland savanna maintained by periodic wildfires (Wright and Bailey 1982). During this study, the region was a shrubland dominated by honey mesquite and lotebush in various stages of regrowth resulting from herbicide application and prescribed fire. The WER was grazed by cattle stocked at 1 animal unit per 12 ha in an 8-paddock rotation system (Long Creek [LC] pasture) and was under continuous yearlong grazing (Grasshopper pasture [GH]; Fig. 1). Individual paddocks within the LC rotational system varied in size from 164 to 499 ha. Prescribed fires were applied to entire paddocks of the LC pasture during February or early March of 1996 (LC2), 1998 (LC5), 2000 (LC8), and 2003 (LC3; Fig. 1); study pastures with no treatment history were also included in this study (LC1, LC6, LC7; Fig. 1). The GH pasture was aerially treated in July 1999 and July 2000 with a mixture of Triclopyr $\{[(3,5,6$-trichloro-2-pyridinyl)oxy $]$ acetic acid $\}$ and Clopyralid (3,6-dichloro-2-pyridine-carboxylic acid) herbicide at a rate of $0.28 \mathrm{~kg}$. $h^{-1}$ each.

\section{Methods}

We used walk-in funnel traps baited with a scratch-grain mixture of sorghum, cracked corn, and wheat to capture bobwhites during February-May of 2003 and 2004. Trap sites were located along the boundaries of study paddocks in both the LC and GH grazing systems (Fig. 1). Captured bobwhites were individually fitted with 6-g necklace-style radio-transmitters in 2003. Backpack-style transmitters were used in 2004 in an attempt to reduce harness slippage and bobwhite mortality. Radio-marked bobwhites were released at the trap site and relocated $\geq 3$ times per week by homing (White and Garrott 1990); efforts were made to space locations where vegetation was measured to $\geq 2$-day intervals to reduce the dependent nature of telemetry locations. Coordinates (latitude, longitude) were recorded at each bob- white telemetry location, and sites were subsequently visited to measure habitat structure. We did not include nest sites or successive locations of bobwhites on a nest in any of the analyses.

We quantified the structural attributes of woody and herbaceous vegetation associated with each bobwhite or bobwhite covey location (used) and a corresponding random point. When multiple marked birds were in the same covey, we recorded data only once per location to maintain independence. A used location was treated as a point that was centered within a habitat patch of a 4-m radius, and measurements were taken along each of 8 compass directions radiating from the point as described in Kopp et al. (1998). Brush canopy cover was estimated using 4-m line intercepts along each of the 8 compass radii (Canfield 1941). A 1.5-m Robel pole was used to measure visual obstruction of vegetation (Robel et al. 1970). We also measured the obstruction angle created by the nearest, tallest obstruction (grass, brush, etc.) to the sample point as an index to the cone of vulnerability (Kopp et al. 1998). The cone of vulnerabilty represents the volume of airspace in which an avian predator has a direct line of sight on a bobwhite (Guthery 2002); obstruction angles range from $0^{\circ}$ (no obstruction) to $90^{\circ}$ (total vertical obstruction). Large obstruction angles represent narrow cones and low exposure to avian predators.

We visually estimated the percent cover of grass, forb, litter, and bare-ground exposure within a $20 \times 50$-cm sampling frame randomly placed along each of the 8 compass radii. Similar measurements were taken at random locations 50-500 m from used locations; distance and direction to random points were chosen using a random number table, and we located the points in the field by using a handheld compass and pacing. Vegetation measurements at used and random locations were made on the same day and within a week of the respective telemetry location. We generated 1000 bootstrap means to describe vegetation variables at used and random locations for the total data set (Mooney and Duval 1993, Lusk et al. 2006). We report results as means with 95\% confidence intervals. Means with nonoverlapping convidence intervals were considered significantly different (Johnson 1999).

We used binary logistic regression (used $=$ 1 , random $=0)$ to model bobwhite selection 
TABLE 1. Means and upper (UCL) and lower (LCL) 95\% confidence limits of vegetation parameters measured at points used by Northern Bobwhites $(n=267)$ and at random points $(n=267)$ on north Texas rangelands during February-August 2003 and February-April 2004. Means and 95\% confidence intervals were generated using 1000 bootstrapped resamples of the raw data.

\begin{tabular}{lrrrrrrr}
\hline & \multicolumn{3}{c}{ Used points } & & \multicolumn{3}{c}{ Random points } \\
\cline { 2 - 3 } \cline { 6 - 7 } Vegetation parameter & LCL & \multicolumn{1}{c}{$\bar{x}$} & UCL & & LCL & $\bar{x}$ & UCL \\
\hline Woody canopy cover $(\%)$ & 24.6 & 29.4 & 36.2 & & 11.7 & 13.9 & 16.0 \\
Visual obstruction & 3.0 & 3.1 & 3.3 & & 2.3 & 2.4 & 2.5 \\
Angle of obstruction $\left({ }^{\circ}\right)$ & 57.8 & 61.0 & 64.2 & & 29.9 & 32.8 & 36.0 \\
Bare ground $(\%)$ & 7.5 & 9.0 & 10.6 & & 11.2 & 13.6 & 16.1 \\
Grass canopy cover $(\%)$ & 34.8 & 36.8 & 38.9 & & 37.6 & 40.0 & 42.3 \\
Forb canopy cover $(\%)$ & 2.4 & 2.9 & 3.5 & & 2.7 & 3.2 & 3.8 \\
Litter $(\%)$ & 40.0 & 50.4 & 52.8 & & 40.2 & 42.6 & 44.9 \\
\hline
\end{tabular}

on the basis of vegetation structural attributes. First, we randomly selected 179 used-random paired data points to build the initial model; this represented $67 \%$ of the total data set. To avoid multicollinearity among vegetation variables, we conducted a pairwise Pearson correlation analysis and simple linear regression analyses to identify correlated pairs of variables. We removed 1 variable of a correlated pair before conducting logistic regression analyses on null (constant only), full (constant and all variables), and reduced models (constant, significant variables); we evaluated each of these models using the significance of the differences in model deviances $(D$; Manly et al. 2002). We evaluated goodness-of-fit and classification ability of the final model using the Hosmer-Lemeshow test $(C$; Hosmer and Lemeshow 2000) and the area under the receiver operator curve (ROC; Fielding and Bell 1997), respectively. The area under the ROC is a measure of the accuracy of the model and is preferred over traditional measures like the percentage correctly classified because it is not dependent on an arbitrary cutoff point for determining class membership (e.g., 0.5; Hosmer and Lemeshow 2000). We assessed the model's predictive ability (e.g., model validation) on a smaller data set of 88 pairs of used-random points using the area under the ROC. We plotted means and 95\% confidence intervals from 1000 bootstrap samples for all significant variables in the model for each study pasture, each season (spring [SPR], summer [SUM]), and each time of day (AM: 07:00-11:00, MID: 11:00-15:00, and PM: 15:00-19:00). All statistical analyses were conducted using SYSTAT v12 (SYSTAT Software, Chicago, IL).
Our data were collected on the same treated study sites between years on the WER; our sites were not spatially replicated nor independent among years, and thus we limit our inferences to our study sites on the WER.

\section{Results}

This study was conducted over a 10-month period from February to August 2003 and from February to April 2004, during which time we radio-marked 81 bobwhites $(n=41$ in 2003; $n$ $=40$ in 2004). Weather constraints and logistics allowed us to measure habitat attributes at 267 pairs of used and random locations. Depredation and collar slippage were high in our study and limited the number of locations we could record for individual birds and precluded traditional home range-level use-availability analysis; radio-marked bobwhites survived on average 38 days (range 1-86) in 2003 and 16 days (range 2-60) in 2004. On average, 5 days (range 1-28) separated locations at which we measured vegetation characteristics.

Locations used by bobwhites had significantly larger mean values of brush canopy cover, angle of obstruction, and visual obstruction than did random locations (Table 1); random locations were characterized by greater percentages of bare ground than bobwhite locations (Table 1). Percent brush cover and visual obstruction were correlated with angle of obstruction $\left(r=0.556, r^{2}=0.308, \mathrm{df}=\right.$ 533, $P<0.001$; and $r=0.512, r^{2}=0.261$, df $=533, P<0.001$, respectively); we chose to retain the angle of obstruction because it integrates multiple attributes of habitat structure into a single variable, which is independent of the type of cover (Harrell and Fuhlendorf 2002, Guthery 2002). Logistic regression on 

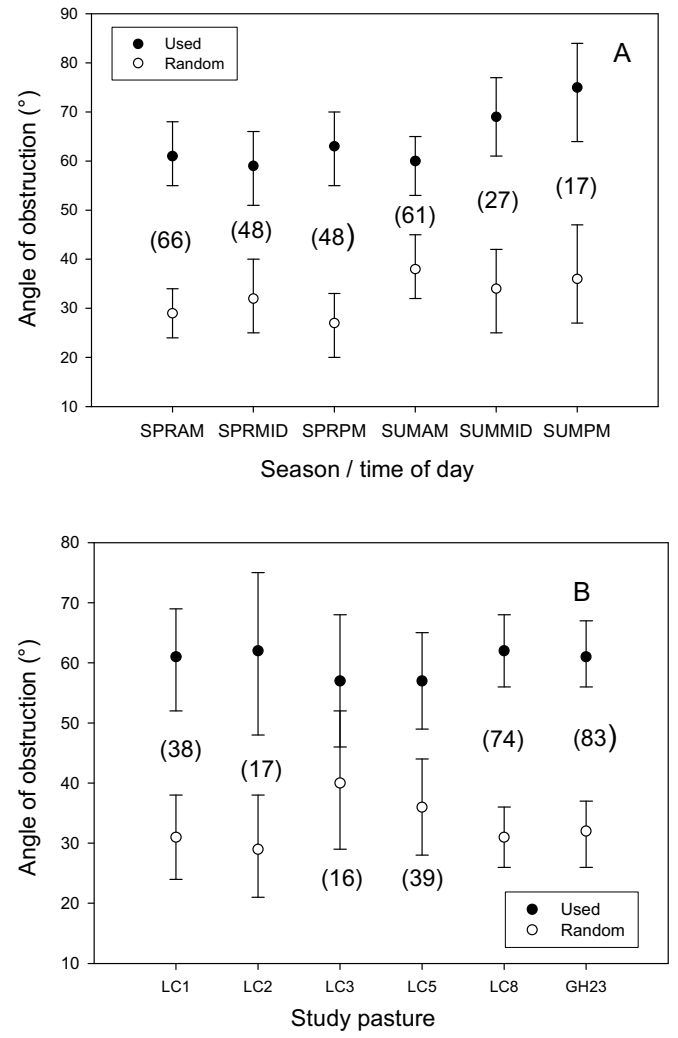

Fig. 2. (A) Mean values for the angle of obstruction $\left(^{\circ}\right)$ measured at points used by Northern Bobwhites and random points during spring (SP: February-April) and summer (SU: May-August) and time of day (AM: 07:00-11:00; MID: 11:00-15:00; PM: 15:00-19:00) on the Waggoner Experimental Ranch in the Rolling Plains of northern Texas. (B) Mean values for the angle of obstruction $\left(^{\circ}\right)$ measured at points used by Northern Bobwhites and random points for individual study pastures on the Waggoner Experimental Ranch in the Rolling Plains of northern Texas. Numbers in parentheses are respective sample sizes. Means were derived from bootstrap resampling of the raw data $(n=1000$ bootstraps). Bars represent $95 \%$ confidence intervals.

the larger portion of the data set produced a best-fit model that contained only the angle of obstruction:

Occurrence $(1,0)=$

$$
\frac{\exp \{-1.937+0.043 \text { (angle of obstruction) }}{1+\exp \{-1.937+0.043 \text { (angle of obstruction). }}
$$

The odds ratio of the full model was $1.04 \pm$ $0.01(\bar{x} \pm 95 \%$ confidence interval), and there was a good fit to the data $(C=10.38, \mathrm{df}=8, P$ $=0.233$ ). The area under the ROC curve was 0.80 , indicating that there was an $80 \%$ proba- bility of correctly classifying each point in a pair of points as a random location or a used location based on the relative difference in their classification scores. When validated on the smaller data set, the model retained its high classification probability (78.4\%). Angles of obstruction were significantly higher at used locations than at random locations across seasons and time of day (Fig. 2A) and across all but 1 study pasture (Fig. 2B).

\section{Discussion}

The differences in vegetative attributes between sites used by bobwhites and random sites in our study were those that reduced exposure to predators based on descriptive comparisons of means and logistic modeling. Our logistic model had a high probability of correctly discriminating used locations from random sites based upon the angle of obstruction. The selection of sites with large obstruction angles was consistent across seasons and times of day, as well as across all but 1 study pasture (Fig. 2A, 2B). Reducing exposure to predators would be especially important to bobwhites of both sex and age classes in late winter and early spring, when food resources would likely be at their seasonal lows requiring coveys to forage longer. Avian predators, including Northern Harriers (Circus cyaneus), Cooper's Hawks (Accipiter cooperii), and Shorteared Owls (Asio flammeus), were common on our study sites until spring migration, and their presence overlapped with covey breakup in the spring. Selection for reduced exposure also would benefit single birds and newly formed pairs, which are more vulnerable to avian predation than large coveys. However, the selection for sites with high obstruction angles continued well into the summer, after most avian predators had migrated north, suggesting that sites with greater vegetation obstruction helped mitigate high midday and late-afternoon summer temperatures (Forrester et al. 1998, Guthery et al. 2005a, Hiller and Guthery 2005). Summer midday loafing coverts selected by brood-rearing bobwhites have been shown to differ from fall and winter coverts based upon their structural attributes for mitigating extreme summer temperatures (Johnson and Guthery 1988); the ability to reduce high ambient temperatures also may be important to late-nesting hens (Guthery et al. 1988). The heat avoidance 
hypothesis and the predator avoidance hypothesis are confounded as hypothetical causes of cover selection because they both lead to the same deduction (Hiller and Guthery 2005).

The cone of vulnerability can be calculated from the angle of obstruction using standard trigonometric equations (Kopp et al. 1998); as angles increase, the cone of vulnerability decreases. The angles we measured at used locations of the total data set produced a mean estimated cone of vulnerability of 494,321 $\mathrm{m}^{3}$ $\left(s_{\bar{x}}=64,038\right)$ which was comparable to estimates for bobwhites from other geographic regions $\left(455,700 \mathrm{~m}^{3}\left[s_{\bar{x}}=25,847\right]\right.$-Kopp et al. $1998 ; 526,000 \mathrm{~m}^{3}\left[s_{\bar{x}}=34,000\right]$-Guthery et al. 2001). Our obstruction angles measured at random sites produced an estimated mean cone value of $1,066,000 \mathrm{~m}^{3} \quad\left(s_{\bar{x}}=37,864\right)$, which is substantially larger than those reported by others (Kopp et al. 1998, Guthery et al. 2001). Estimated bootstrapped mean angles at used sites differed significantly from those at random sites; confidence intervals for these mean angles for random sites were much narrower than those for used sites. This suggests that sites suitable for bobwhites on our study area may not be abundant in a relatively uniform environment. The consistent differences we documented across all but 1 study pasture suggest that broad-scale application of fire or herbicide may have limited the availability of suitable sites for bobwhites. Fire and herbicide applications directly affect the canopy cover and height of live woody plants and can eliminate the benefits of woody plants in providing escape and thermal cover. However, differences between used and random locations also existed in the untreated pasture (LC1, Fig. 2B), suggesting that habitat structure on the WER may be generally inadequate and that our management practices may have had a neutral effect; bobwhite densities were low across these and other treatment pastures on the WER (Ransom and Schulz 2007).

We expected a difference in ground cover attributes to exist among used and available locations because of the numerous studies that identify the importance of bare-ground and forb cover to bobwhites (Hammerquist-Wilson and Crawford 1981, Campbell-Kissock et al. 1984, Wilkins and Swank 1992, Taylor and Guthery 1994, Taylor et al. 1999). However, the only difference that existed was greater bare- ground cover at random sites than at used sites. We expected used sites to have more bare ground. Percent bare-ground estimates for both used and random sites were low, and the difference was not great $(<5 \%$, Table 1$)$, which makes interpretation of this difference difficult.

Guthery (2002) has argued from selectionratio modeling that similarity among used and random habitat features provides evidence that the habitat feature is optimally distributed in time and space for bobwhites. Alternatively, the lack of selection for ground cover attributes may represent the concept of slack: the ability of different patch configurations to provide optimal habitat for bobwhites (Guthery 1999); contextually, then, a lack of selection for ground cover characteristics may be confounded with the differences found in brush canopy cover, visual obstruction, and angle of obstruction. The conservative management of grazing on our study sites may also provide an explanation. Light stocking rates contributed to the relatively uniform levels of grass, litter, and forb cover for both used and random sites. Light stocking rates would have also produced a lower degree of soil disturbance and lower levels of forb cover than one would observe at heavier stocking rates. As a result, there may not have been a gradient among these attributes large enough for bobwhites to select from. The narrow range of the confidence intervals for these ground cover variables at random sites supports this hypothesis (Table 1).

Our study was not directed at addressing survival of bobwhites, but survival of our radiomarked birds was low. Guthery and Lusk (2004) and Abbott et al. (2005) have argued that radio-transmitters may handicap bobwhites' survival ability, but more recent work in the southeastern United States failed to document a transmitter effect on bobwhite survival (Palmer et al. 2007, Terhune et al. 2007). The possibility of a transmitter effect does posit the hypothesis that radio-transmitters also may affect habitat selection. We cannot address this hypothesis with our data, except to point out that our data from used locations harmonize well with other published studies (Kopp et al. 1998, Guthery et al. 2001).

The importance of woody cover to bobwhites has been recognized for some time (Johnson and Guthery 1988), but until recently, little attention has been given to quantifying how much woody cover is required, especially in the 
context of range management practices directed at controlling woody encroachment for livestock forage production. Estimated woody cover requirements have typically ranged between 5\% and 15\% (Guthery 1986, Fulbright and Guthery 1995), but these estimates have not been based upon rigorous field studies. Our data indicate that woody cover at used sites averaged 29\%, and the data correspond well with other studies that show that bobwhites use habitat patches that average $\geq 30 \%$ woody cover (Kopp et al. 1998, Guthery et al. 2005b, Hiller et al. 2007). This suggests that woody cover requirements for bobwhites may be much larger than previously thought and may impact land management in the Rolling Plains of Texas, where private ranches are still relatively large and brush management practices are applied at large spatial scales. Such an approach on our study sites may not have provided optimal habitat for bobwhites in terms of optimal cover requirements. We believe that the differences we found illustrate this and highlight the importance of incorporating species requirements into range management practices directed at controlling invasive woody plants.

\section{Conclusions}

Bobwhites on our study sites selected locations based on habitat attributes that provided significantly higher levels of screening cover than were randomly available. The magnitude of difference in mean values for percent woody canopy cover and angle of obstruction suggests that suitable sites for bobwhites may not have been abundant in our managed landscapes. Our data may not be typical of previously published studies, however, because the aerial herbicide and prescribed fires were applied as 1-time treatments at large landscape scales. Consequently, broad-scale application of measures directed at reducing woody cover may not be desirable where bobwhites are a management interest, but more research is warranted. Ground-cover characteristics typically thought to be important to bobwhites, such as grass and forb cover, did not appear to be important or sufficiently different to affect habitat selection.

\section{ACKNOWLEDGMENTS}

Financial and logistical support was provided by a College of Agriculture and Life Sciences
G. Rollie White Scholarship to J.S. Wagner, the Department of Wildlife and Fisheries Sciences at Texas A\&M University, College Station, and the Texas A\&M Agricultural Experiment Station, Vernon. We thank the W.T. Waggoner Ranch for access to their property to conduct this research. B. Collier, M. Castellano, W.E. Pinchak, J. Sij, J. Slosser, and 2 anonymous reviewers provided helpful comments toward improving this manuscript.

\section{Literature Cited}

Abbott, C.W., C. Brad Dabbert, D.R. Lucia, and R.B. Mitchell. 2005. Does muscular damage during capture and handling handicap radio-marked Northern Bobwhites. Journal of Wildlife Management 69:664670 .

Adams, C.E., J.K. Thomas, and C.W. Ramsey. 1992. A synopsis of Texas hunting leases. Wildlife Society Bulletin 20:188-197.

Archer, S. 1989. Have southern Texas savannas been converted to woodlands in recent history? American Midland Naturalist 134:545-561.

Archer, S., C. Scifres, C.R. Bassham, and R. Maggio. 1988. Autogenic succession in a subtropical savanna: conversion of grassland to thorn woodland. Ecological Monographs 58:111-127.

CampBell-Kissock, L., L.H. Blankenship, and L.D. WHite. 1984. Grazing management impacts on quail during drought in the northern Rio Grande Plain, Texas. Journal of Range Management 37:442-446.

Canfield, R.H. 1941. Application of the line intercept method in sampling range vegetation. Journal of Forestry 39:388-394.

Cram, D.S., R.E. Masters, F.S. Guthery, D.M. Engle, AND W.G. Montague. 2002. Northern Bobwhite population and habitat response to pine-grassland restoration. Journal of Wildlife Management 66:1031-1039.

Fielding, A.H., AND J.F. BELl. 1997. A review of methods for the assessment of prediction errors in conservation presence/absence models. Environmental Conservation 24:38-49.

Forrester, N.D., F.S. Guthery, S.D. Kopp, and W.E. CoHen. 1998. Operative temperature reduces habitat space for Northern Bobwhites. Journal of Wildlife Management 63:1506-1511.

Fulbright, T.E., AND F.S. Guthery. 1995. Mechanical manipulation of plants. Pages 339-354 in P.R. Krausman, editor, Rangeland wildlife. The Society for Range Management, Denver, CO.

Gould, FW. 1975. Texas plants-a checklist and ecological summary. Revised edition. Texas Agricultural Experiment Station, Miscellaneous Publication 585.

Guthery, F.S. 1986. Beef, brush, and bobwhites: quail management in cattle country. Caesar Kleberg Wildlife Research Institute Press, Texas A\&M UniversityKingsville.

1997. A philosophy of habitat management for Northern Bobwhites. Journal of Wildlife Management 61:291-301.

1999. Slack in the configuration of habitat patches for Northern Bobwhites. Journal of Wildlife Management 63:245-250. 
2002. The technology of bobwhite management: the theory behind the practice. Iowa State Press, Ames.

Guthery, F.S., N.M. King, W.P. Kuvlesky, JR., S. DeSteFano, S.A. Gall, AND N.J. Silvy. 2001. Comparative habitat use by three quails in desert grassland. Journal of Wildlife Management 65:850-860.

Guthery, F.S., N.E. Koerth, and D.S. Smith. 1988. Reproduction of Northern Bobwhites in semi-arid environments. Journal of Wildlife Management 52 144-149.

GuTHERY, F.S., AND J.J. LusK. 2004. Radio-telemetry studies: are we radio-handicapping Northern Bobwhites? Wildlife Society Bulletin 32:194-201.

Guthery, F.S., A.R. Rybak, S.D. Fuhlendorf, T.L. Hiller, S.G. Smith, W.H. Puckett, JR., and R.A. Baker. 2005a. Aspects of the thermal ecology of bobwhites in north Texas. Wildlife Monographs 159:1-36.

Guthery, F.S., A.R. Rybak, W.R. WALSh, S.D. FuhlenDORF, AND T.L. HiLLER. 2005b. Quantifying usable space for wildlife with use-availability data. Journal of Wildlife Management 69:655-663.

Hammerouist-Wilson, M.M., and J.A. Crawford. 1981. Response of bobwhites to cover changes within three grazing systems. Journal of Range Management 34: 213-215.

Harrell, W.C., AND S.D. FuhlendorF. 2002. Evaluation of habitat structural measures in a shrubland community. Journal of Range Management 55:488-493.

Hiller, T.L., AND F.S. Guthery. 2005. Microclimate versus predation risk in roost and covert selection by bobwhites. Journal of Wildlife Management 69:140149.

Hiller, T.L., F.S. Guthery, A.R. RybaK, S.D. FuhlendorF, S.G. Smith, W.H. Puckett, Jr., and R.A. Baker. 2007. Management implications of cover selection data: Northern Bobwhite example. Journal of Wildlife Management 71:195-201.

Hosmer, D.W., and S. Lemeshow. 2000. Applied logistic regression. 2nd edition. John Wiley \& Sons, Inc., New York.

JACKSON, A.S. 1969. A handbook for bobwhite quail management in the West Texas Rolling Plains. Bulletin No. 48, Texas Parks and Wildlife Department, Austin.

Johnson, D.B., AND F.S. Guthery. 1988. Loafing coverts used by Northern Bobwhites in subtropical environments. Journal of Wildlife Management 52:461-469.

Johnson, D.H. 1999. The insignificance of statistical significance testing. Journal of Wildlife Management 63:763-772

Koerth, B.H. 1995. Chemical manipulation of plants. Pages 312-337 in P.R. Krausman, editor, Rangeland wildlife. The Society for Range Management, Denver, CO.

Kopp, S.D., F.S. Guthery, N.D. Forrester, and W.E CoHEN. 1998. Habitat selection modeling for Northern Bobwhites on subtropical rangeland. Journal of Wildlife Management 62:884-895.

Lusk, J.J., S.G. Smith, S.D. Fuhlendorf, AND F.S. GuTHERY. 2006. Factors influencing Northern Bobwhite nest-site selection and fate. Journal of Wildlife Management 70:564-571
Manly, B.F.J., L.L. McDonald, D.L. Thomas, T.L. MCDOnALD, AND W.P. ERICKSON. 2002. Resource selection by animals: statistical design and analysis for field studies. 2nd edition. Kluwer Academic Publishers, Boston, MA

Mooney, C.Z., And R.D. Duval. 1993. Bootstrapping: a nonparametric approach to statistical inference. Sage University, Newbury Park, CA.

Palmer, W.E., and S.P. Wellendorf. 2007. Effect of radiotransmitters on Northern Bobwhite annual survival. Journal of Wildlife Management 71:1281-1287.

Ransom, D., JR., AND G.G. Schulz. 2007. Northern Bobwhites and postfire succession. Journal of Wildlife Management 71:565-570.

Renwald, J.D., H.A. Wright, and J.T Flinders. 1978. Effects of prescribed fire on bobwhite quail habitat in the Rolling Plains of Texas. Journal of Range Management 31:65-69.

Riggs, R.A., S.C. Bunting, And S.E. Daniels. 1995. Prescribed fire. Pages 295-319 in P.R. Krausman, editor, Rangeland wildlife. The Society for Range Management, Denver, CO

Robel, R.J., J.N. Briggs, A.D. Dayton, and L.C. HurlBURT. 1970. Relationships between visual obstruction measurements and weight of grassland vegetation. Journal of Range Management 23:295-297.

SCIFrES, C.J. 1980. Brush management: principles and practices for Texas and the Southwest. Texas A\&M University Press, College Station.

Scifres, C.J., and W.T. Hamilton. 1993. Prescribed burning for brushland management: the south Texas example. Texas A\&M University Press, College Station.

Spears, G.S., F.S. Guthery, S.M. Rice, S.J. DeMaso, and B. ZaigLin. 1993. Optimum seral stage for bobwhites as influenced by site productivity. Journal of Wildlife Management 57:805-811.

TaYlor, J.S., K.E. Church, and D.H. Rusch. 1999. Micro-habitat selection by nesting and brood-rearing Northern Bobwhite in Kansas. Journal of Wildlife Management 63:686-694.

Taylor, J.S., AND F.S. Guthery. 1994. Components of Northern Bobwhite brood habitat in southern Texas. Southwestern Naturalist 39:73-77.

Terhune, T.M., D.C. Sisson, J.B. Grand, and H.L. StribLING. 2007. Factors influencing survival of radiotagged and banded Northern Bobwhites in Georgia. Journal of Wildlife Management 71:1288-1297.

White, G.C., AND R.A. GARRoTt. 1990. Analysis of wildlife radio-tracking data. Academic Press, San Diego, CA.

Wilkins, R.N., AND W.G. SWANK. 1992. Bobwhite habitat use under short duration and deferred rotation grazing. Journal of Range Management 45:549-553.

Wright, H.A., AND A.W. BaILEy. 1982. Fire ecologyUnited States and southern Canada. Wiley InterScience, John Wiley \& Sons, Inc., New York.

Received 9 April 2007 Accepted 17 October 2007 